\title{
Yeni-liberal Kurumsalcılık Çerçevesinde Çin'in Komşuluk Diplomasisi: Hu Jintao ve Xi Jinping Dönemlerine Karşılaştırmalı Bir Bakış¹
}

\author{
DOI:10.26466/opus.594562
}

\author{
$*$ \\ Cemre Pekcan* \\ * Dr. Öğr. Üyesi, Çanakkale Onsekiz Mart Üniversitesi, Biga İ̈BF, Çanakkale / Türkiye \\ E-Posta:. cemrepekcan83@hotmail.com ORCID: 0000-0001-7339-2680
}

\section{Öz}

Ekonomik anlamda karşılıklı bağımlılığın artması, devletler arasında işbirliğini gerekli kılmaktadır. Paylaşılan bu ekonomik çıkarlar da uluslararası kuruluşların önemini artırmaktadır. Robert Keohane ve Joseph Nye'ın öncülü̆ğ̈̈nü yaptı̆̆ı yeni-liberal kurumsalcılık yaklaşımı temel olarak, devletler arasında barışın sağlanması ve sürdürülmesi için uluslararası kuruluşları önemine vurgu yapmaktadır. Günümüzde Çin'in barışçl bir gelişim mi izleyeceği yoksa statükoya başkaldıran bir güç mü olacağı ile ilgili tartışmalar devam ederken Çin, barış̧ıl gelişimini vurgulamak için, uluslararası kuruluşlara katılımını artırmakta ve komşularla ilişkilerini ön planda tutarak bu bağlamda çeşitli projeler geliştirmektedir. 1970'lerin sonlarında başlayan iyi komşuluk politikası çerçevesinde gerek Hu Jintao'nun 'barış̧̧l gelişim', 'uyumlu dünya' gibi politikaları, gerekse Xi Jinping'in Kuşak Yol projesi, atılan önemli adımlar olarak değerlendirilmektedir. Ancak tabi ki Güney Çin Denizi ve $A B D$ ile yaşanan ticaret savaşları iyi komşuluk politikasını zora sokan unsurlardır. Bu bağlamda çalışmada, Çin'de 2003-2013 yillar arasında Devlet Başkanliğı yapan Hu Jintao ve 2013'te Parti Genel Sekreteri olarak seçilen ve hala görev yapmakta olan Xi Jinping dönemlerinde Çin'in komşuluk diplomasisi incelenerek, neoliberal kurumsalcllı çerçevesinde değerlendirmede bulunulacaktır.

Anahtar Kelimeler: Yeni-liberal kurumsalcılık, komşuluk diplomasisi, karşılıklı bağımlılık, Çin, barışçıl gelişim

\footnotetext{
${ }^{1}$ Bu çalışma 5-7 Eylül 2018 tarihlerinde Romanya'da düzenlenen XVIII. European Conference on Social and Behavioral Sciences'ta sunulmuş ve yalnızca özet olarak yer almış bildirinin genişletilmiş halidir.
} 


\title{
China's Neighbourhood Diplomacy in the Framework of Neoliberal Institutionalism: A Comparative Perspective of $\mathrm{Hu}$ Jintao and $\mathrm{Xi}$ Jinping Periods
}

\begin{abstract}
Increasing mutual economic interdependence necessitates cooperation between states and shared economic interests increase the importance of international institutions. Neo-liberal institutionalism -pioneered by Robert O. Keohane and Joseph S. Nye- basically emphasizes the importance of international institutions in order to provide and maintain peace between states. Today, while the debate on whether China will follow a peaceful development or become a revisionist power continues, China, enhances its participation in international organisations to emphasize its peaceful development and promotes good neighbourhood diplomacy through various projects. Within the framework of good neighbourhood policy, both Hu Jintao's policies such as 'peaceful development' and 'harmonious world' and Xi Jiping's 'Belt and Road' initiative are considered as important steps. However, problems such as South China Sea and trade wars with the US create difficulties for China's good neighbourhood policy. In this context, this study aims to analyse China's neighbourhood diplomacy within the framework of neo-liberal institutionalism by comparing Hu Jintao (president between 2003-2013) and Xi Jinping (president since 2013) periods.
\end{abstract}

Keywords: Neo-liberal institutionalism, neighbourhood policy, interdependence, China, peaceful development 


\section{Giriş}

Uluslararası ilişkiler teorileri, uluslararası olayların nedenlerini araştırır ve bunu yaparken temel aldıkları ya da vurguladıkları odak noktası bakımından ayrılırlar. Bu da oldukça geniş yelpazeli teorik yaklaşımlar doğurur.

Uluslararası ilişkilerde, devleti temel aktör olarak ele alan ve anarşi, ulusal çıkar, güç mücadelesi gibi kavramlara odaklanan realizmin uluslararası olayları açılama gücü 1962 Küba Füze Krizi, onu takip eden Vietnam Savaşı ve 1970'lerde yaşanan OPEC petrol krizi gibi olaylarla yetersiz kalınca, karşılıklı ticaret ve işbirliğine vurgu yapan yeni liberal bakış açısı ortaya çıkmıştır (Wiltze, 2014, s.137-141). Uluslararası ilişkilerde devletin yanı sıra bireyleri ve sivil toplum kuruluşlarını temel aktör olarak ele alan liberal yaklaşım, uluslararası olayları birim düzeyinde analiz ederek, sistem düzeyinde sonuçlara ulaşmaktadır (Arı, 2006, s.367-368). Kısaca, liberalizm; özgürlük, demokrasi, hukuk devleti, karşılıklı bağımlılık, serbest piyasa ekonomisi gibi kavramlara öncelik vererek, uluslararası barış konusunda daha iyimser bir yaklaşım sergilemektedir.

Yeni-liberaller ya da neo-liberaller, devletler arasında işbirliğinin mümkün olduğunu ve bunun da 'karşılıklılık' ilkesine dayandığını iddia ederler. Bu fikirlerini desteklemek için de 'Mahkûmun İkilemi' örneğini verirler. Bu modelde kısaca, birlikte suç işlediklerine dair yargılanan iki mahkûm vardır. Buna göre suçu önce itiraf eden kişi serbest kalacak, diğeri idam edilecek, eğer aynı gün itiraf ederlerse indirimli ceza alacaklar, eğer ikisi de itiraf etmezse silah bulundurmaktan kısa süreli ceza alacaklardır. Aralarında haberleşme olmayan mahkûmlar için en rasyonel strateji her ikisinin de suçu itiraf etmesidir. (Arl, 2006, s.259-264; Goldstein vd., 2015, s. 122-124; Keohane, 1984, s.68-69). Mahkûmun ikilemi aslında işbirliğinin zorluğunu gösteren bir örnektir. Mahkûmlar için en kârlı durum işbirliği yapıp suçu itiraf etmeyerek kısa süreli ceza almak iken, mahkumlar aldatılma korkusu ya da diğerinin niyetinden bihaber olduklarından işbirliğine gitmekten kaçınmaktadır. Ancak; bu örnekten yola çıkarak, oyun tekrar tekrar oynandığı takdirde devletler, kendi kaçınma hamlelerine karşın, karşı tarafın da kaçınacağını düşünerek, karşılıklılık stratejisi 
nedeniyle işbirliğine doğru giderler. Devletlerin uzun dönemde çıkarlarını sağlamlaştırması açısından vardıkları rasyonel sonuç için de temel unsur, uluslararası kurumların ortaya çıkmasıdır (Goldstein vd., 2015, s.138).

II. Dünya Savaşı' ndan sonra Birleşmiş Milletler (BM), Uluslararası Para Fonu (IMF), Dünya Bankası gibi uluslararası örgütler kurulmaya başlanmış ve 1980 'lerle birlikte ticari ve mali ilişkilerin önemi arttıkça bu kuruluşlar daha da önemli hale gelmiştir. Bu da uluslararası kuruluş ve bölgesel entegrasyonların rejim teorisi altında çalışılmaya başlanmasına yol açmıştır. (Stein, 2008, s.203).

Rejim teorisinin öncülerinden Stephen Krasner'e göre rejim; uluslararası ilişkilerde, belli bir konuyla ilgili, aktörlerin beklentilerinin bir noktaya yöneldiği, dolaylı ya da açlk ilkeler, normlar, kurallar ve karar alma prosedürüdür (Krasner, 1983, s.2). Keohane ve Nye ise rejimi; davranışları düzenleyen ve etkilerini kontrol eden kurallar, normlar ve prosedürler ağını içeren 'bir takım yönetimsel düzenlemeler' olarak tanımlamaktadırlar (Keohane vd., 1977, s.19). Young ise rejimi; bazı faaliyetlerdeki eylemleri düzenleyen sosyal kurumlar olarak nitelendirmekte ve tüm sosyal kurumlar gibi bunların da, taraflar arasındaki ilişkileri düzenleyen bir takım kurallar veya konvansiyonlara bağlı rolleri içeren pratikler olduğunu ifade etmektedir (Young, 1989, s.12-13).

Rejim teorisyenleri, devletlerin uluslararası politikanın ana aktörleri ve devlet davranışının güç ve çıkar kaynaklı olduğunu kabul eder. Ayrıca oyun teorisi gibi çatışma analizlerini kullanır ve uluslararası kuruluşların kişisel çıkara dayalı kurulduğunu iddia ederler (Stein, 2008, s.203-204). Diğer bir ifadeyle, devleti temel aktör olarak ele alan rejim teorisi, devletlerin ortak çıkarlarının söz konusu olduğu alanlarda, devletler arasında çoğu alanda işbirliği ve düzenlemelerin artması ve rejim oluşturulmasıyla, barış ve güvenliğin sağlanacağını öne sürmektedir (Arı, 2006, s.497). Rejim teorisi, Robert Keohane ve Joseph Nye'ın öncülüğünü yaptığını yeni-liberal kurumsalcılığı canlandırmıştır.

Yeni-liberallere göre uluslararası işbirliğinin koşulu ve sürekliliği, uluslararası kurumların yaratılmasına bağlıdır (Dunne vd., 2016, s.149). Bazı düşünürlere göre yeni-liberalizm; "liberal uluslararası ilişkiler teorisinin uluslararası kolektif sonuçları elde etmek konusunda uluslararası kurumlarm oynadıklar role odaklanan bir varyasyonudur ve bu nedenle genel olarak 'neo-liberal kurumsalcılık' adını da alır" (Dunne vd., 2016, s.132). 
Günümüzde ekonomik anlamda karşılıklı bağımlılı̆̆ın artması, devletler arasında işbirliğini gerekli kılmakta ve bu paylaşılan ekonomik çıarlar, uluslararası kurum ve kuralların oluşturulması için bir talep yaratmaktadır. Uluslararası kurumların fonksiyonlarına vurgu yapan bu iyimser yaklaşımı savunanları Keohane, 'institutionalists' yani kurumsalcılar olarak adlandırmaktadır (Keohane, 1984, s.7). Diğer taraftan, rejim kavramı da zaman içerisinde kurum kavramıla değişmiştir. Bunun sebebi de; ekonomi, siyaset bilimi, sosyoloji alanlarındaki kurum çalışmalarının yeniden ortaya çıkmasıyla, uluslararası ilişkiler alanındakilerin bunlarla düşünsel düzeyde bağlantı kurabilmesidir. Bu alt dallardaki resmi kurumları inceleyen 'eski kurumsalcılar', daha geniş bir alana odaklanan 'yeni kurumsalcılar'la yer değiştirmiştir (Stein, 2008, s.204). Bu açıklamalardan da anlaşılabileceği gibi yeni-liberalizm, rejim teorisi ve yeni-liberal kurumsalcilık zaman zaman birbirinin yerine kullanılabilen kavramlar olmaktadir.

Keohane kitabında dünya politik ekonomisindeki işbirliği modellerini ve uluslararası rejimlerin işbirliğini nasıl kolaylaştırdığını incelediği için, 'işbirliği' kavramına da açıklık getirmek gereklidir. Keohane, işbirliğini 'uyum/düzen' kavramından ayırır. Uyum; aktörlerin kendi çıarları için izledikleri politikaların, otomatik olarak diğerlerinin hedeflerine ulaşmasını kolaylaştırdığı durumlar için söz konusudur. İşbirliği ise, mevcut durumda uyum içerisinde olmayan birey ya da örgütlerin, müzakere süreci yani politika koordinasyonu yoluyla uyumlulaştırılması anlamına gelir. Diğer bir ifadeyle, hükümetler arası işbirliği, bir hükümetin izlediği politikaların, diğer hükümetlerin hedeflerine ulaşmasında kolaylaştırıcı bir rol oynadığ durumlarda, politika koordinasyon süreci sonucunda ortaya çıkar (Keohane, 1984, s.51-52). Burada da işbirliğini kolaylaştırıcı unsurlar olarak uluslararası kurumlar ortaya çıkmaktadır.

Kurumsalcıları realistlerden ayıran en önemli nokta; kurumsalcıların, karşılıklı bağımlılığın daha fazla işbirliğine yönlendireceğini savunurken, realistlerin bunun aksine, gücün yayılmasının birinin düzen yaratmasına zarar vereceği görüşünde olmalarıdır (Keohane, 1984, s.9). Yeni-liberaller, devletlerin ortak çıkarlarını gerçekleştirmeleri için uluslararası rejimlerin rolüne vurgu yaparlar. Devletleri, yalnızca kendi mutlak çıkarlarını düşünen rasyonel egoistler olarak nitelendiren yeni-liberallere göre, uluslararası politika yalnızca çatışma alanı değildir, genelde işbirliği sayesinde 
devletler daha fazla kazanç elde ederler. Ancak devletler işbirliği konusunda karşı tarafa güvenemezler, burada rejimler devreye girer ve davranışlardaki şeffaflığı artırarak, güvensizliğin azaltılmasına yardımcı olur (Hasenclever vd., 2000, s.7).

Keohane işbirliğini hegemonik ve hegemonik olmayan işbirliği olarak ayırmıştır. İkinci Dünya Savaşı'ndan sonra yaklaşık 15-20 yıl kadar uluslararası ilişkilerde hegemon güç olan $\mathrm{ABD}$ döneminde, hegemonyacı işbirliği olduğunu söyleyen Keohane'e göre 1960'ların ortalarından itibaren ABD'nin büyük kaynak sağladığı uluslararası ekonomik rejimler çökmeye başlamıştır (Keohane, 1984, s.243-244). Keohane'e göre ABD bu hegemonyasını yeniden sağlayamayacağı için günümüzde bağımsız devletler arasında hegemonik olmayan işbirliklerinin olması gerekmektedir. Bu işbirlikleri daha zor kuruluyor olsa da, hegemonya aşındıkça, uluslararası rejimlere ihtiyaç artmaktadır. Bu rejimler, antlaşmaları kolaylaştırmaları, hükümetler arasındaki ticari işlemlerin maliyetini düşürmeleri, müzakereler için zemin hazırlamaları, hükümetler arasındaki bilgi akışını daha sağlıklı ve kaliteli şekilde sağlamaları ve karşılıklılık çerçevesinde bir denetim mekanizması oluşturmaları gibi sebeplerle büyük öneme sahiptirler (Keohane, 1984, s.244-245).

Yeni-liberal kurumsalcılık, günümüzde Çin'in yükselişini en iyi açıklayan teorilerden biridir. Bilindiği gibi, Çin'in yükselişinin barışçıl mı olacağı yoksa ABD’nin hegemonyasına başkaldırıp daha saldırgan bir politika mı izleyeceği sorusu uzun süredir tartışılagelen bir sorudur. Bu bağlamda ortaya atılmış birçok teori vardır. Çin tehdidi algısını besleyen teorilerden biri neo-realizmin temsilcilerinden John J. Mearsheimer'in 'saldırgan realizm'idir (offensive realism). Saldırgan realizm, devletlerin nasıl hayatta kalabilecekleriyle ilgilenir ve bu teoriye göre devletin en önemli hedefi uluslararası sistemde hegemon güç olmaktır. Hayatta kalabilmek ve hegemon güç olabilmek için de güce sahip olmak gerektiğinden, devletler giderek daha saldırgan hale gelirler (Mearsheimer, 2001).

Bir diğer teori de Abramo Fimo Kenneth Organski'nin 1958'de yayınladığı Dünya Politikası (World Politics) adlı kitabındaki güç geçişi teorisidir (power transition theory). Organski devletleri başat güç, büyük güçler, orta büyüklükteki devletler ve küçük devlet olmak üzere dört gruba ayırmıştır. Organski'ye göre, yükselen bir güç eğer statükodan memnun olmazsa, eninde sonunda hegemon güce baş kaldıracaktır (Organski, 1958). 
Bu algıyı yıkmak için Çin, Konfüçyüs'e atıfta bulunan dış politika ilkeleri ve söylemler oluşturmakta, her fırsatta statükodan memnun olduğunu ve hegemonya kurma amacında olmadığını dile getirmektedir. Tabi aynı zamanda Çin, uluslararası kuruluşlara da katılımını artırmakta ve bölgede barış ve istikrarın sağlanması için komşularla ilişkilerini ön planda tutarak konuyla ilgili çeşitli projeler geliştirmektedir. Bu bağlamda çalışmada, Çin'de 2003-2013 yılları arasında Devlet Başkanlığı yapan Hu Jintao ve 2013'te Parti Genel Sekreteri olarak seçilen ve hâlâ görev yapmakta olan Xi Jinping dönemlerinde Çin'in komşuluk diplomasisi incelenerek, neoliberal kurumsalcılık çerçevesinde değerlendirmede bulunulacaktır.

\section{Çin'in Komşuluk Diplomasisi}

1945-49 arası komünistler ve milliyetçiler arasında yaşanan iç savaş sonucunda komünistlerin galip gelmesiyle Çin Halk Cumhuriyeti kurulmuş ve Komünist Parti Genel Sekreteri Mao Zedong Çin'in ilk Devlet Başkanı seçilmiştir. Mao döneminde kendi ekonomisine ve iç düzeni sağlamaya odaklanan Çin, 1976'da Mao'nun ölümüne kadar dışa kapalı bir politika izlemiştir.

Mao'dan sonra Deng Xiaoping'in de facto lider olarak başa gelmesiyle ${ }^{2}$ Çin, tarım, sanayi, ulusal savunma, bilim ve teknoloji gibi alanları güçlendirmek adına 'Dört Modernizasyon' adı verilen reform programını uygulamaya koymuş ve bu reformlarla ekonomik olarak dışa açılmıştır. Bu dışa açılmayla birlikte Çin, bölgesel güvenlik ve barışı sağlamak ve dış dünyada etkisini artırmak ve tabi ki dünyadaki imajını düzeltmek adına 'periphery policy (周边, zhōubiān)' olarak bilinen 'iyi komşuluk/çevre politikası'nı kabul etmiştir (Cabres, 2011). İyi komşuluk politikasının başlangıcı 1950'li yıllara kadar götürülebilir. 1953 yılında, Zhou Enlai, Hindistan'dan gelen delegelerle görüşürken ‘barış içinde bir arada yaşamanın beş ilkesi'ni önermiştir. Bu ilkeler; toprak bütünlüğüne ve egemenliğe karşılıklı

\footnotetext{
${ }^{2}$ Mao'dan sonra Jiang Zemin'e kadar aslında Hua Guafeng, Hu Yaobang ve Zhao Ziyang kısa süreyle Devlet Başkanı olarak görev yapmıştır ama bu dönemlerde Deng Xiaoping, Devlet Başkanı sıfatıyla olmasa da Çin Merkezi Askeri Komisyonu ve Merkezi Danışma Komisyonun başı olarak Çin'de en üstün (paramount) lider olarak anılıyordu ve Çin'in gelişimine en büyük katkıyı sunduğundan dolayı Mao'dan sonra gelen kişi olarak anılmaktadır.
} 
sayg1, karşılıklı saldırmazlık, birbirlerinin iç işlerine müdahalede bulunmama, eşitlik ve ortak payda ile barış içinde bir arada yaşamayı içermektedir. 1956'da Çin Komünist Partisi'nin 8. Kongresi'nde Çinli liderler, bu beş ilkeyi vurgulayarak, komşularıyla bu beş ilke temelinde iyi komşuluk ilişkileri geliştirmeleri gerektiğini dile getirmişlerdir. Bu ilkelerden yola çıkarak Çin, kurulduktan sonra ilk 10 yıl içinde 36 ülkeyle diplomatik ilişki kurmuştur (Zhang, 2013, s.21-22).

1980 ve 90'lar Çin'in dışa açılımıyla birlikte ekonomik büyümeye odaklandığı yıllardır. Bu yıllarda Çin, komşularıyla da ekonomik, güvenlik ve askeri alanlarda işbirliği yapmıştır. Bu bağlamda ASEAN ülkelerine ASEAN-Çin Serbest Ticaret Bölgesi önerisi ve 1996'da Rusya, Kazakistan, Kırgızistan ve Tacikistan'la birlikte Şangay İşbirliği Örgütü'nü kurmaları önemli gelişmelerdir (Zhang, 2013, s.30).

Çin için en önemli dönüm noktalarından biri 1989 Tiananmen Meydanı olayları $^{3}$ olmuştur. Bu olaylardan sonra Çin, özellikle insan hakları ihlallerinden dolayı birçok ülkeyle ilişkisinde problem yaşamıştır. Bu durumu toparlamak ve izolasyondan kurtulmak için Çin, diplomasisini yeniden kurmaya, komşu ülkelerle ilişkilerini geliştirmeye ve bölgesel ve uluslararası örgütlere üye olmaya başlamıştır. Üye olduğu örgütler çerçevesinde bu dönemde en öne çıkan örgüt Şangay İşbirliği Örgütü'dür (ŞIÖ). 1996'da Çin, Rusya, Kazakistan, Kırgızistan ve Tacikistan'ın kurduğu Şangay Beşlisi, 2001'de Özbekistan'ın da katılımıyla ŞïÖ'ye dönüşmüştür.

Deng Xiaoping'den sonra başa gelen Jiang Zemin döneminde de Çin, komşuluk diplomasisi izleyerek Asyalı komşularıyla ilişkileri onarma yoluna gitmiş ve Tiananmen'de zarar gören imajını düzeltmeye çalışmıştır. (Lanteigne, 2009, s.109). Dışa açılmadan bu yana Çin dış politikasının önemli bir unsuru olan komşuluk diplomasisi ilk kez 16. Parti Kongresi'nde, 2002 yılında vurgulanmıştır. Bir yıl sonra da Çin'in komşularına yönelik hedeflerini tanımlamak amacıyla 'iyi komşuluk, güvenli komşuluk ve zengin/refahlı komşuluk' kavramı dönemin Başbakanı Wen Jiabao tarafından kullanılmıştır (Swaine, 2014, s.3).

${ }^{3}$ Çin'de 1989 yılının 15 Nisan'ı ve 4 Haziran'ı arasında meydana gelen; öğrencilerin, aydınların ve işçilerin önderliğinde gerçekleşen ve hükümet tarafından kanlı bir şekilde bastırılan gösterilerdir. 


\section{Hu Jintao Dönemi Çin Dış Politikası ve Komşuluk Diplomasisi}

Hu Jintao, 2002 yılının Kasım ayında düzenlenen Çin Komünist Partisi'nin 16. Ulusal Kongresi'nde, ÇKP Merkez Komitesi'nin Genel Sekreteri olarak seçilmiş, 2003 yılının Mart ayında düzenlenen 10. Ulusal Halk Kongresi'nde de Çin Cumhurbaşkanı olarak seçilmiştir. Aynı kongrede Wen Jiabao ise Başbakan seçilmiştir. (Guoli, 2008, s.102).

$\mathrm{Hu}$ Jintao iktidara geldiğinde, ABD ve diğer Batılı güçlerle çatışmadan kaçınmak amacıyla Deng Xiaoping'in 1990'ların başında ortaya attığı taoguangyanghui yani düşük bir profil izleme stratejisini devam ettirmiş ve bu sayede ekonomisini güçlendirerek Japonya'nın önüne geçmiş ve dünyanın ikinci büyük ekonomisi haline gelmiştir. Hu Jintao döneminde Çin dış politikasında dört ilke ön plana çıkmaktadır. Bunlar; barışçl yükseliş, barışçl gelişim, uyumlu toplum ve uyumlu dünya ilkeleridir.

ÇKP eski başkan yardımcısı Zheng Bijian, 3 Kasım 2003'te Asya için düzenlenen Boao Forumu'nda yaptığı konuşmasında ilk kez barışçıl yükseliş kavramını dile getirmiştir. 'Çin'in Barışçıl Yükselişi için Yeni Bir Yol ve Asya'nın Geleceği' başlıklı konuşmasında, Zheng Bijian, 'barışçıl yükseliş' kavramını; “Çin'in ekonomik küreselleşmeye katıldığı, sosyalizmin Çin değerleriyle yeniden inşa edildiği bir stratejik yol" olarak tanımlamıştır. (Guoli, 2003, s.544). Barışçıl yükseliş, Çin'in yükselen bir güç olmasına rağmen, uluslararası statükoyadan memnun olduğunu, yeni bir dünya düzeni yaratma amacı olmadığını, mevcut uluslararası düzen içerisinde gelişimini sürdüreceğini ifade eder (Lanteigne, 2009, s.31).

Barışçıl yükseliş kavramı daha sonra, saldırgan bir yükseliş gibi algılanabileceği gerekçesiyle değiştirilmiş ve barışçıl gelişim (和平发展) şeklinde ifade edilmeye başlanmıştır. Çin, 2005'de yayımladığı resmi raporunda barışçıl gelişimin amaçlarını; "kendi gelişimi için barışçıl bir uluslararası ortam oluşturmaya ve kendi gelişimiyle dünya barışına katkıda bulunmaya çalışmak; reform ve yenilikler yaparak ve başka ülkelere değil, kendine güvenerek gelişim sağlamak; küresel ekonomiye uyum sağlamak ve diğger ülkelerle ortak faydaya dayalı bir gelişim izlemek; barış, gelişim ve işbirliği yoluyla, uyumlu bir dünya yaratılmasına katkıda bulunmak", şeklinde açıklamıştır (Pekcan, 2017, s.1140). 
Uyumlu toplum (和谐社会) kavramı, Çin'in yalnızca ekonomik gelişimden ziyade, ülke içindeki fakir-zengin arasındaki gelir farkının azaltılması, çevre kirliliği, rüşvet gibi sosyal konulara da odaklanılmasını ifade eder (Geis vd., 2009, s.75-94). Uyumlu dünya (和谐世界) kavramı ise, Hu Jintao'nun 2005'te BM Zirvesi'nde yaptığı konuşmada vurgulanmıştır. $\mathrm{Hu}$, konuşmasında eşitlik ve şeffaflık altında medeniyetlerin farklılıklarının korunmasına çabalandığı, tüm medeniyetlerin bir arada ve dayanışma içinde yaşadığı, uluslararası ilişkilerin daha demokratik olduğu uyumlu bir dünyadan bahsetmiştir (United Nations Summit, 2005). Uyumlu dünya kavramının üç temel faktörü; ortak güvenlik (共同安全), ortak refah (共同繁榮) ve uyumlu ilişkilerdir (和諧關係) (Chao vd., 2008, s.87). Su Hao'ya göre uyumlu dünya kavramı, Çin'in barışçıl dış politikasını bir üst seviyeye taşıyan stratejik bir kavramdır (Su, 2008, s.34). Kısacası uyumlu toplum Çin'in kendi gelişimine odaklanan, ulusal bir kavramken; uyumlu dünya bu kavramın uluslararası ilişkilere genişletilmiş halidir.

$\mathrm{Hu}$ Jintao döneminde komşuluk diplomasisi Hu'nun uyumlu dünya politikasının bir parçası olarak görülmüştür (Swaine, 2014, s.3). Yalnız bu çerçevede Çin'in çevre ya da komşu ülke tanımı da net değildir. Uzmanlar bu konuyu farklı farklı yorumlamaktadır. Bazıları Çin'in yalnızca sınır komşularını ele alırken; bazı uzmanlar komşu kavramını üç halka şeklinde genişletmektedir. İlk halka ya da iç halka Çin'le sınırı paylaşan 14 ülkeyi ifade etmektedir. İkinci halka ya da orta halka, iç halkanın hemen dışında kalan deniz ülkeleri ve Çin'le doğrudan sınırı olmayan Batı Pasifik'ten Hint Okyanusu'na kadar olan alanı ve aynı zamanda Orta Asya'nın bazı bölgeleri ve Rusya'yı ifade etmektedir. Son ya da dış halka ise Afrika, Avrupa ve Amerika'ya kadar genişlemektedir (Swaine, 2014, s.4). Kısacası Çin'in komşuluk diplomasisi Çin'in sınır komşularıyla başlayıp giderek tüm dünyayı kapsayan bir halkaya dönüşmektedir.

Hu Jintao döneminde komşuluk diplomasisi çerçevesinde birçok ülkeye ziyarette bulunulmuş ve çeşitli alanlarda bu ülkelerle ikili anlaşmalar imzalanmıştır. Örneğin 25 Nisan 2005'te Hu, Endonezya Cumhurbaşkanı Susilo ile görüşmede bulunarak Çin ve Endonezya arasında Stratejik Ortaklık Kurulmasına Dair Ortak Bildiri'yi imzalamıştır (Embassy of the People's Republic of China in the Republic of Indonesia, 2015). Bu dönemde ayrıca Çin'in artık sorumluluk sahibi bir güç olduğunu göstermek adına da girişimlerde bulunulmuştur. Bu bağlamda atılan en önemli 
adımlardan biri; Kuzey Kore'nin, 2003'te Nükleer Silahların Yayılmasını Önleme Anlaşması'ndan (NPT) çekildiğini açıklamasıyla, sorunun barışçıl yollarla çözülmesi amacıyla Çin'in, 2003-2008 yılları arasında, ABD, Kuzey Kore, Güney Kore, Japonya ve Rusya'nın katıldığı 'Altılı Müzakereler'e ev sahipliği yapmasıdır (Liang, 2018). Müzakereler boyunca bazı olumlu ilerlemeler kaydedilse de, 2009'da Kuzey Kore'nin müzakerelerden çekildiğini açıklamasıyla süreç son bulmuştur.

$\mathrm{Hu}$ Jintao'nun uyumlu dünya ve barışçl gelişim politikası paralelinde gelişen iyi komşuluk politikası bağlamında Çin öncelikle, sınır problemleri yaşadığı Rusya'yla 2004'te sınır problemlerine son vermek amacıyla bir anlaşma imzalamıştır. 2700 mil uzunluğundaki sınırın 4300 kilometresinde sorun yaşayan iki ülke, bu anlaşma ile sınır problemlerini büyük ölçüde çözerek diğer alanlarda işbirliğinin de önünü açmışlardır (The New York Times, 2004). Hu yalnızca Rusya değil, tarihte çatışma yaşadığı Hindistan ve Vietnam'la da problemleri çözmeye yönelik girişimlerde bulunmuştur. 2005'te Hindistan'la Himalaya bölgesini kapsayan alanda s1nır problemlerini çözmek üzere bir anlaşma imzalamış, aynı yıl Vietnam’a da bir ziyarette bulunarak, politik ve ekonomik ilişkileri geliştirmek adına, içinde sınır probleminin çözümüne de yer veren bir teklifte bulunmuştur (Xiaobo, 2018).

Bölgesel güvenlik açısından da, 2011 yılında Çin, Laos, Myanmar ve Tayland, Mekong Nehri'nde insan ve uyuşturucu kaçakçılığı, terör saldırıları gibi suçları önlemek ve güvenliği sağlamak adına ortak devriye kararı almışlardır (Xinhua News, 2018). Bu da Çin'in komşularıyla ilişkilerinin gelişmesi ve bölgenin güvenliği açısından önemli bir adım olarak değerlendirilebilir.

Hu Jintao dönemi, bazı uzmanlarca farklı yorumlanmaktadır. Bazı akademisyenlere göre Çin'in başarısındaki iki önemli unsur; karşılıklı ekonomik bağımlılık ve iyi komşuluk politikasıdır ancak $\mathrm{Hu}$, komşuluk politikası konusunda bunun tam tersini yapmış ve komşu ülkelerin ABD'yi bölgeye davet etmesine ve bölgede güçlenmesine sebep olmuştur (Tonesson, 2012). Bunun sebeplerinden biri; 2008 ABD Başkanlık seçimlerinde Barack Obama'nın Başkan seçilmesiyle birlikte 'pivot to Asia' yani Asya'ya dönüş/Asya'ya yönelim stratejisiyle Asya'yı önceliğine almış olmasından 
kaynaklanmaktadır. Obama'nın Asya'yı önceliği yapması ise Çin'i çevreleme stratejisi olarak algılanmış ve bazı konularda Çin'in daha 'iddialı' davranmasına yol açmıştır.

Hu döneminde Çin'in komşularıyla arasının açılmasına verilen örnekler arasında; Kuzey Kore, 2010'da Güney Kore'ye ait bir gemiyi batırd1ğında Çin'in bu olayı kınamayı reddetmesi, 2010' da problemli adalar olan Senkaku/Diaoyu adaları civarında Japonya'nın tutukladığ 1 Çinli balıkçı teknesi kaptanı olayında, Çin'in olayı ihtiyatlı bir şekilde çözmek yerine bazı ortak projeleri reddetmesi ve açıktan tehditte bulunması, Güney Çin Denizi'nde Vietnam ve Filipinlerle yaşanan anlaşmazlıklar gibi olaylar yer almaktadir (Tonesson, 2012).

Kısaca, Hu Jintao döneminde komşuluk diplomasisi bağlaminda daha çok bölge ülkeleriyle ikili anlaşmalar ve işbirliklerinin ön plana çıktığı görülmektedir. Diğer taraftan, ABD'nin bölgeye ilgisi ve Çin'i çevreleme politikası nedeniyle, Çin'in özellikle Japonya, Filipinler gibi ABD'nin müttefiki ülkelerle bozulan ilişkileri söz konusudur.

\section{Xi Jinping Dönemi Çin Dış Politikası ve Komşuluk Diplomasisi}

Mart 2013'te devlet başkanı olarak göreve başlayan ve 2017'de yeniden seçilen Xi Jinping dönemi ile birlikte Çin'in komşuluk diplomasisi de yeni bir evreye girmiştir. Xi'nin diş politika ilkelerinde iki unsur ön plana çımaktadır. Bunlar; Çin karakteristiği ile büyük güç diplomasisi (zhonguo tese daguo waijiao) ve büyük güç ilişkileri için yeni modeldir (xinxing daguo guangxi).

Büyük güç diplomasisi, Çin'in artık gelişmekte olan bir ülke değil, sorumluluklarını yerine getirmeye hazır, büyük bir güç olduğunu ifade etmektedir. Çin'in sorumluluklarını yerine getirmek konusunda en büyük katkısı daha çok BM bünyesinde gerçekleşmektedir. Büyük güç ilişkileri için yeni model ise; Xi'nin 2012'de Washington ziyareti sırasında dile getirdiği bir kavramdır. Hegemonya ya da çatışma yerine, saygı, eşitlik ve karşlıklı faydaya dayalı bir ilişkiyi ifade etmektedir (Qi, 2015, s.350).

Xi'nin dış politikasında öne çıkan diğer unsur da Deng'in taoguangyanghui yani düşük bir profil izleme politikasının yerini 'sosyalizmin büyük başarısı için çabala' ( Embassy of the People's Republic of China in the Commonwealth of Australia, 2017) ya da bazı kaynaklarda 
'başarı için çabala' (Nien-Chung, 2016, s.83) ilkesinin almış olmasıdır. Tüm bu yeni ilkeler Xi Jinping'in geçmiş liderlere kıyasla çok daha aktif bir dış politika izlediğinin ve izleyeceğinin göstergesidir. Bu bağlamda aslında, göreve gelmeden önce çok daha pasif bir politika izleyeceği tahmin edilen Xi Jinping, aksine göreve geldikten bir hafta sonra ilk denizaşırı turunu yapmış, Rusya ve Tanzanya'yı ziyaret etmiş ve Güney Afrika'daki BRICS Zirvesi'ne katılmıştır. Bir rapora göre 2013'te Mart-Ekim ayları arasındaki yedi aylık süreçte Xi Jinping toplamda 33 gününü yurtdışında geçirmiş, Avrupa, Afrika, Latin Amerika ve Asya'da çeşitli uluslararası toplantılara katılıp, liderleri ziyaret etmiştir (Zhang, 2015, s.7).

Xi, ülke içerisinde de daha sert ve aktif politikalar uygulamış, bu bağlamda öncelikle Komünist Parti'nin rolünü güçlendirmiştir. Parti kadroları içerisinde rüşvete karşı bir kampanya başlatan $\mathrm{Xi}$, bunun yanı sıra terörizmle savaş, yabancı hükümet dişı örgütlerin rollerinin sınırlanması, medya üzerindeki kontrolün artırılması gibi uygulamalar getirmiştir (Bader, 2016, s.9).

Komşuluk diplomasisi açısından incelendiğinde, Xi Jinping, Çin'in barışçıl gelişimi açısından komşuluk diplomasisine önceliğine alarak, konuyla ilgili konferanslar düzenlenmesini sağlamış ve 'yakınlık', 'karşlıklı fayda', 'kapsayıcılık' ve 'samimiyet' gibi kavramlarla komşuluk diplomasisinin tanımını belirlemiştir (Xulong, 2013). 2013' de Xi “iyi bir komşu altınla takas edilemez" (China Daily, 2017) diyerek bölgede barış ve güvenliğin sağlanması için, komşu ülkelerle iyi ilişkilerin önemini vurgulamıştır.

Komşuluk diplomasisi çerçevesinde yine aynı yıl 25 Ekim 2013'te Pekin'de Komşuluk Diplomasisi Çalışma Konferansı düzenlenmiştir. Bu konferansta Xi, çevre ülkelerin Çin'in stratejik gelişimi açısından oldukça önemli olduğunu, dostluk ve işbirliğinin komşu ülkelerle ilişkilerde temel ilkesi olduğunu, komşu ülkelerin Çin'le daha yakın olması ve Çin'i desteklemeleri için daha faydalı şeyler yapacaklarını vurgulamıştır. (China Council for International Cooperation on Environment and Development, 2013). 2013 Konferansı aynı zamanda Kuşak Yol Projesi için de başlangıç olmuştur. Kuşak Yol projesiyle birlikte Çin'in diplomasisinde temel öncelik de $\mathrm{ABD}^{\prime}$ den komşu ülkelere kaymıştır. 
21. Yüzyılın İpek Yolu olarak da anılan Kuşak Yol Projesi, 70'ten fazla ülkeyi kapsayan, Asya ve Avrupa hattındaki ülkeler arasında ulaşım, yatırım ve ticaret bağlantısı kuran bir projedir. Proje, eski İpek Yolu'nun Avrupa'ya kadar genişletilmiş şekli olarak düşünülebilir. Kuşak-Yol projesi hem Çin'i iktisadi olarak kalkındıracak hem de Çin'i Rusya'ya, Orta Asya'ya, Güneydoğu Asya'ya, Güney Asya'ya, Batı Asya'ya, Körfez ülkelerine, Orta ve Doğu Avrupa'ya ve Afrika'ya bağlayacaktır. Projenin kapsamındaki ülkelerin çoğu yeni yeni kalkınmakta olan ülkeler olduğundan bu proje ile oluşturulacak pazar, tüm bu ülkelerin ekonomilerine ciddi bir katkı sağlayacaktır. (Durdular, 2016, s.94). 1 trilyon dolardan fazla maliyete sahip olacağı düşünülen proje için Çin şimdiden 210 milyar dolardan fazla yatırım yapmıştır (The Guardian, 2018).

Proje kapsamında karadan ve denizden iki ayrı güzergâh oluşturulması düşünülmektedir. Karadan olan hat İpek Yolu Ekonomik Kuşağı, deniz hattı ise Deniz İpek Yolu'dur. Bunların ikisi birlikte Kuşak Yol Projesi olarak anılmaktadır. İpek Yolu Ekonomik Kuşağı da kendi içerisinde temel olarak iki alt kısma ayrılmaktadır. Pekin'den başlayıp, Rusya, Almanya ve sonunda İskandinav ülkelerine ulaşan Kuzey Hattı ve Pekin'den başlayıp, Uygur Özerk Bölgesi, Afganistan, Kazakistan, Macaristan ve sonunda Paris, Londra, Hamburg ya da Lizbon'a ulaşan Orta Hat (Chaisse, 2018, s.164). Deniz İpek Yolu ise, Çin limanlarını, Singapur-Malezya-Hint Okyanusu-Kızıl Deniz'i Akdeniz'e bağlayan Süveyş Kanalı yoluyla Afrika ve Avrupa'ya bağlamaktadır (Bocutoğlu, 2017, s.265-270).

Xi Jinping, 2014'teki Asya'da İşbirliği ve Güven Arttırıcı Önlemler Konferansı'nda, Asya Altyapı Yatırım Bankası'nın (Asian Infrastructure Investment Bank -AIIB), kurulmasını önermiş ve Çin'in bankaya gelecekte yaklaşık kırk milyar dolarlık destekte bulunacağını vaat etmiştir (Durdular, 2016, s.80). Bankanın amacı Asya bölgesindeki altyapı yatırımları için finansman sağlamaktır, kısaca bankanın önemli bir kredi mekanizması işlevi bulunmaktadir.

Çin için komşularıyla artan ekonomik bağları, bölgenin güvenlik ve istikrarını da etkilemektedir. Bu bağlamda Kamboçya, Myanmar, Laos, Moğolistan gibi küçük ülkeler Çin'in hegemonik etkisi için hayati derecede önem taşımaktadır (Liping, 2017). Bu çerçevede; örneğin, Xi 2014 Ekim ayında Moğolistan'ın Ulan Batur şehrindeki konuşmasında, Çin'in top- 
lam ithalat ve ihracatının 4.16 trilyon doları aştığını, gelecekteki 5 yıl içerisinde Çin'in ithalatının 10 trilyon doları aşacağını ve Çin'in getirdiği piyasa fırsatlarından yakın komşu Moğolistan'ın faydalanmaya hazır bulunması gerektiğini dile getirmiştir. Çin ve Moğolistan'ın coğrafi yakınlıklarına vurgu yapan Xi, Moğolistan'a bir Çin atasözüyle atıfta bulunmuştur, s. "Ay ışığını ilk, su kenarındaki çadır alır" (A water-front pavilion gets the moonlight first) (CGTN America, 2014). Xi Jinping 2015'te Singapur'a düzenlediği bir seyahatte de, komşuluğun Çin'in etraflı diplomasisi içinde önemli bir yere sahip olduğunu, Çin'in komşularıyla barış, istikrar ve gelişimi sağlamayı görev edindiğini ve Kuşak-Yol projesinden tüm komşuların yarar sağlayarak Çin'in başlıca işbirliği ortakları olacağını açıklamıştır (Xue vd., 2016).

Pakistan da bu projede büyük önem taşıyan ülkelerden biridir. 2017 Kasım ayında Xi, Pakistan ve Çin'in stratejik işbirliği ortakları olduğunu ve Çin'in komşuluk diplomasisinde Pakistan'ın her zaman önceliği olduğu açıklamıştır. Pakistan'la ilişkileri geliştirmek adına Kuşak-Yol Projesi, Çin-Pakistan Ekonomik Koridoru, ikili ticari, savunma, terörü önleme, kültür alanlarında çeşitli anlaşmalar vardır. Yetkililere göre Çin'in Çin-Pakistan Ekonomik Koridoru'nu geliştirmek için 60 milyar dolardan fazla yatırım yaptığ1 söylenmektedir (NDTV, 2017).

Diğer tarafta Kuşak-Yol Projesi, ABD'nin bölgedeki gücü ve çıarları açısından büyük bir tehdit oluşturmaktadır. ABD Başkanı Barack Obama'nın, iktidara geldiğinde bölgeye yönelik olarak başlattığı 'pivot to Asia' stratejisiyle başlayan politikaları, Çin'i çevreleme kapsamında Trans-Pasifik Ortaklığı'nın (TPP) kurulmasıyla devam etmiştir. Bölgede ticareti geliştirmeyi amaçlayan ve 12 ülkenin imzaladığı anlaşmadan ABD, Trump'ın iktidara gelmesiyle çekilmiştir. ABD'nin bölgeden çekilmesi bir nevi Çin'in bölgede önünü açmıs görünmektedir.

Çin'in Kuşak-Yol başta olmak üzere bölgedeki aktif politikaları karşısında ABD de, Dışişleri Bakanı Mike Pompeo'nun 'Indo-Pasifik Ekonomik Vizyonu' çerçevesinde bölgeye yatırımlarını artırarak sürdürmektedir. Teknoloji, enerji ve altyapı için 113 milyon dolarlık hükümet yatırımının yanı sıra, ABD, Japonya ve Avusturalya arasında üçlü bir yatırım anlaşması yapılması planlanmaktadır. Ayrıca ABD, Moğolistan'la da yeni su kaynaklarının geliştirilmesi için 350 milyon dolarlık bir yatırım anlaşması yapmıştır (Jiangtao vd., 2018). 


\section{Xi Jinping'in Dış Politikasına Yönelik Eleştiriler}

Xi Jinping, iktidara geldiğinden bu yana Çin'in sorumluluk sahibi büyük bir güç olduğunu, uluslararası sistemi değiştirmek istemediğini, sistemin kurallarına uyumlu hareket edeceğini ve barışçıl gelişimini sürdüreceğini dile getirse de Xi'nin gerek dış politikası gerekse geliştirdiği Kuşak-Yol gibi projeler çeşitli eleştirilere maruz kalmaktadır.

Örneğin Çin'in Kuşak-Yol projesinin, Çin'in hem yakın komşularıyla hem de uzak bölgedeki ülkelerle ilişkilerini karşılıklı bağımlılık çerçevesinde geliştireceği varsayılsa da, bazı uzmanlar projeyi ve Xi Jinping'in diş politika uygulamalarını Çin'in uluslararası sistemin kurallarına yeniden ve kendi çıkarlarına göre yazmak istemesi şeklinde yorumlamaktadır (Rühlig, 2018).

Kuşak-Yol projesini eleştirenlerden biri de Foreign Policy yazarlarından Tanner Greer'dir. Greer'e göre Kuşak-Yol projesi büyük bir başarısızlıktır. Proje için ülkelere, planlanandan çok daha fazla para harcanmasına rağmen, bu ülkelerden henüz ne yatırımcılar için ne de Parti için bir kazanım sağlanmamıştır. Hatta çevre ülkelerden bazı olumsuz tepkiler gelmektedir. Örneğin, Maldivlerin yeni cumhurbaşkanı Kuşak-Yol'u hemen terk edilmesi gereken büyük bir aldatmaca ve borç tuzağı olarak görmektedir. Malezya Başbakanı da projeyi 'yeni sömürgecilik' olarak nitelendirmiştir. Bangladeş'te de en aktif işleyen Kuşak-Yol projelerinden biri olan Çin Limanı Mühendislik Şirketi rüşvet suçlamasıyla kara listeye alınmıştır (Greer, 2018).

Diğer bir taraftan Doğu Asya bölgesi her an bir sıcak çatışmanın yaşanabileceği en riskli bölgelerden biridir ve bölgede birçok çözülemeyen sorun mevcuttur. Bu sorunlar karşısında Çin, bir yandan bölge ülkeleriyle komşuluk ilişkilerini geliştirmeye çalışırken, diğer yandan da ekonomik ve askeri gücünü kullanarak, sorunlar karşısında bölge ülkelerini zorlamakta ve baskı yapmaktadır. Justyna Szczudlik-Tatar'a göre, Çin'in Kuşak-Yol gibi projeleri görünürde Çin'in temel katkı sağlayıcı olduğu ve bölge ülkelerinin ciddi fayda sağlayacağı iyi niyetli girişimler gibi görünse de, aslında bunun altında yatan şey Çin'in iyi niyetinden ziyade bölgede liderliğini kurabilmesi ve ABD etkisini sınırlandırabilmesi için yapılan girişimler (Szczudlik-Tatar, 2015). 
Çin'in komşuluk diplomasisini zorlayan en büyük sorunlardan biri Güney Çin Denizi sorunudur. Denizin neredeyse tamamında hak iddia eden Çin, askeri harcamalarını da giderek artırmakta ve bu sayede denizde hak iddia eden diğer devletler üzerinde baskı kurabilmektedir. Çin'in askeri bütçesi 2019 yılı için \%7.5'lik bir artışı hedeflemektedir. Her ne kadar 2018 yılındaki \%8.1'lik artışa göre daha düşük gibi görünse de bölgede askeri tansiyonun azalmasına bir etkisi olacak gibi görünmemektedir (Olsen, 2019).

Güncel olarak Çin'in iyi komşuluk diplomasisini zorlayacak gelişmelerden biri de Hindistan-Pakistan arasındaki Keşmir sorunudur. Hindistan'ın, Hindistan ve Pakistan arasında özerk bölge olarak adlandırılan Keşmir'in bu statüsünü tek taraflı olarak kaldırma kararıla birlikte, iki ülke arasında ilişkiler gerilmiştir. Sorunun Çin'i ilgilendiren kısmı ise; iki ülkenin bölgeye getireceği istikrarsızlığın yanı sıra, Hindistan'ın Çin'le de henüz netleşmemiş sınır problemleri olmasıdır. Hindistan, Keşmir hamlesinden sonra, Çin'in yönetiminde bulunan ama kendisinin olduğunu iddia ettiği Aksai Chin bölgesi için de bir hamle yapabilir ve bu durum iki ülkeyi çatışmaya sürükleyebilir.

\section{Sonuç}

1970'lerin sonunda başlayan reformlarla, ekonomik olarak diş dünyaya açılan Çin, hızlı bir ekonomik büyüme gerçekleştirmiş ve günümüzde ABD'den sonra ikinci büyük ekonomi konumuna gelmiştir (The World Bank). Çin'in bu hızlı büyümesi zaman içerisinde 'Çin tehdidi' algısına yol açmış ve durumdan endişe duyan ABD, Çin'i bölgede çevrelemek adına çeşitli girişimlerde bulunmuştur.

Çin, hem ekonomik büyümesine devam etmek hem de Çin tehdidi algısını kırmak amacıyla öncelikle komşu ülkelerle ilişkilerini geliştirme yoluna gitmiştir. Bu bağlamda Çin, yeni-liberal kurumsalcıların da desteklediği, ekonomik anlamda karşılıklı bağımlılığın artmasının devletler arasındaki işbirliğini gerekli kılacağı ve bu ekonomik çıarların uluslararası rejim ve kurumların oluşturulmasına öncülük edeceği düşüncesi ile çeşitli girişimlerde bulunmuştur. 
Komşularıyla ilişkilerine bakıldığında Çin, 1949 yılından bu yana uzunca bir süre güç kullanımı ve çatışmaları önlemek için erteleme stratejisi izlemiştir. Hu Jintao'nun son iki yılında ise Çin, özellikle tartışmalı deniz alanları konusunda daha agresif bir tutum takınmış ve Tayvan, Tibet ve Sincan bölgesinin yanı sıra Güney Çin Denizi'ni de temel çıarları içerisine koymuştur (Suisheng, 2012). Hu Jintao döneminde, ABD'nin 'pivot to Asia' stratejisinin de etkisiyle konuyla ilgili somut bir adım atılamasa da, komşuluk diplomasisi bağlamında daha çok bölge ülkeleriyle ikili anlaşmalar ve işbirliklerinin ön plana çıktığı görülmektedir.

Mao'dan sonra Çin'in en güçlü lideri olarak anılan Xi Jinping dönemi ise Çin'in, çok daha proaktif bir politika izleyerek, özellikle komşularla ilişkilerde daha somut adımların atıldığı, önemli gelişmelerin yaşandığı bir dönemdir. Xi döneminde artık kendini sorumluluk sahibi büyük güç olarak konumlandıran Çin'in attığı en büyük adım, modern İpek Yolu projesi olan ve 70'ten fazla ülkeyi kapsayan Kuşak Yol projesidir.

Xi Jinping döneminde ortaya atılan Kuşak Yol projesi gibi projeler, Çin'in hem sınır komşularıyla hem de diğer ülkelerle arasında karşlıklı bağımlılık ve işbirliğini artırmakta, bunun da yeni liberal kurumsalcılığın iddia ettiği gibi devletler arasında güvensizliğin azaltılmasında rol oynayarak, savaş/çatışma ihtimalini azaltması beklenmektedir. Ancak son dönemlerde Çin-ABD arasında yaşanan ticaret savaşları, Hindistan-Pakistan arasındaki Keşmir sorununun alevlenmesi, Çin'in askeri harcamalarını artırması, bazı komşu ülkelerin Kuşak-Yol projesini Çin'in hegemonyasını kurmak istemesi olarak algılaması gibi sebepler Çin'in iyi komşuluk diplomasisini sarsıyor görünmektedir. Kuşak-Yol projesi henüz yeni bir proje olduğundan getirilerinin ne olacağını belirlemek şu an güç görünmektedir. Projenin gidişatı ve komşuluk diplomasisi, Xi'nin mevcut problemler karşısında izleyeceği stratejilere bağlıdır.

Sonuç olarak Hu Jintao ve Xi Jinping dönemleri karşılaştırıldığında Xi Jinping döneminde Çin'in komşuluk diplomasisi bağlamında çok daha büyük projeler geliştirdiği görülmektedir. Yeni liberal kurumsalcılık bağlamında değerlendirildiğinde de Xi Jinping'in dış politika ilkeleri, yap1lanlar ve söylemler yeni liberal kurumsalcılık teorisiyle örtüşmektedir. Ancak yeni-liberal kurumsalcılık bağlamında atılan adımların bölgede istikrarın sağlanmasında yeterli olup olmayacağ $\mathrm{Xi}^{\prime}$ 'nin mevcut problemler karşısında atacağı adımlara bağlıdır. 


\title{
EXTENDED ABSTRACT
}

\section{China's Neighbourhood Diplomacy in the Framework of Neoliberal Institutionalism: A Comparative Perspective of Hu Jintao and Xi Jinping Periods \\ *}

\author{
Cemre Pekcan \\ Çanakkale Onsekiz Mart University
}

With the establishment of international organizations such as the UN, World Bank or IMF and the emergence of globalization during 1980s, regime theories began to come into prominence in the IR discipline. In international relations, regime theory, which can be defined as the indirect or explicit principles, norms, rules and decision-making procedure where the expectations of the actors are directed to a certain point, reviwed neoliberal institutionalism pioneered by Robert Keohane and Joseph Nye. Neo-liberal institutionalism, which is a positive approach, claims that interdependence between states increased cooperation and due to this cooperation, wars will be reduced.

Today, the 'China Threat' theory, which is influenced by Western IR theories, is one of the most debated subjects. China has made several attempts to break this perception of threat such as; emphasizing Confucian values, creating political principles of 'peaceful development', 'harmonious world', 'harmonious society', expressing that China will not seek to be the hegemon etc. At the same time, China is increasing its participation in international organizations, keeping good relations with the neighbours to ensure peace and security of the region and developing various projects.

People's Republic of China, established in 1949, followed a closed policy until Mao's death in 1976. After Mao, one of the most influential persons of Chinese history, Deng Xiaoping, started a reform programme which is called 'Four Modernizations' and opened up China to the world economically. With this opening up, China adopted periphery policy (周 
边, zhōubiān) which is also known as good neighbourhood policy, to provide peace and security in the region and to restore its image. After Deng Xiaoping, Jiang Zemin came to power and during his period, he tried to improve relations with neighbouring countries through good neighbourhood policy, after 1989 Tiananmen Square incident.

Neighbourhood diplomacy, which is an important element of Chinese foreign policy, was first emphasized in 2002, during 16th Party Congress. After a year, Chinese Prime Minister Wen Jiabao used terms such as 'good neighbourhood, secure neighbourhood and prosperous neighbourhood' to describe China's goals for its neighbours.

During the presidency of $\mathrm{Hu}$ Jintao between 2003-2013, four principles came into prominence. These are; peaceful rise, peaceful development, harmonius society and harmonious world. All these principles are basicly stated that China is a developing power, however, instead of creating a new world order such as previous powers, it will develop within the international status-quo and norms while contributing to the world peace. Good neighbourhood policy during Hu Jintao period was seen as a part of Hu's harmonious world policy.

Withing the framework of good neighbourhood policy, Hu Jintao visited several countries and signed bilateral agreements in many different fields. During Hu period, one of the most important initiative was the SixParty Talks hosted by China between 2003-2008 to solve the North Korea's nuclear problem peacefully. In addition, the agreement with Russia in 2004 to solve the border disputes and joint patrol in Mekong River with Laos, Myanmar and Thailand to prevent crimes such as drug trafficking and terrorism were other important initiatives of $\mathrm{Hu}$ period.

China's neighbourhood diplomacy has entered a new phase with Xi Jinping who started his presidency in 2013 and relected in 2017. With Xi Jinping, China began to state that it is no longer a developing power anymore, instead it is a great power ready to fulfill its responsibilities. $\mathrm{Xi}$ Jinping pays special importance to neighbourhood diplomacy and on October 25, 2013, Neighbourhood Diplomacy Working Conference was held in Beijing. This conference, at the same time was a start for Belt and Road Project. With this project, neighbouring countries were given priority instead of the US. 
Belt and Road Project includes more than 70 countries and established transport, investment and trade links between Asia and Europe. Project can be considered as an extended version of ancient Silk Road to Europe. For China, which has already heavily invested to project, the huge market created by this project will contribute to the economies of the countries through mutual benefit and cooperation.

In addition to Belt and Road, small countries such as Cambodia, Myanmar, Laos and Mongolia are also very important for China's hegemonic influence and stability of the region. Therefore, $\mathrm{Xi}$ made special visits to these countries and signed many agreements. Also on November 2017, Xi stated that Pakistan and China are strategic cooperation partners and $\mathrm{Pa}-$ kistan has a priority in China's neighbourhood diplomacy.

Comparing the neighbourhood diplomacy of two leaders, it is seen that bilateral relations were more important in Hu Jintao period however, he took wrong steps regarding some regional problems. Of course Obama's pivot to Asia and containment policy had an important effect on this. During $\mathrm{Xi}_{\mathrm{i}}$ Jinping period, it is seen that much larger projects were developed in the context of neighbourhood diplomacy. When evaluated in the context of neo-liberal institutionalism, Xi Jinping's policy principles, actions and discourses coincide with the theory of neo-liberal institutionalism. However, whether the steps taken as part of neo-liberal institutionalism will be sufficient to ensure the stability of the region will depend on Xi's actions against current problems.

\section{Kaynakça / References}

75th Joint Patrol on Mekong River Completed.( Ekim 26, 2018). Xinhua News, 05.11.2018 tarihinde http://www.xinhuanet.com/english/asiapacific/2018-10/26/c_137560703.htm adresinden erişilmiştir.

Arı, T. (2006). Uluslararası ilişkiler teorileri: Çatışma, hegemonya, işbirliği, 4. Basim, İstanbul: Alfa Yayınları,

Bader, J. A. (2016). How Xi Jinping sees the World... and why, Asia Working Group Paper 2: Order from Chaos, Foreign Policy at Brookings.

Bocutoğlu, E. (2017). Çin'in "bir kuşak-bir yol” projesinin ekonomik ve jeopolitik sonuçları üzerine düşünceler. International Conference on Eurasian Economies, 265-270. 
Cabres, M. D. (2011). China's peaceful rise and the good neighbor policy. 01.12.2018 tarihinde http://www.eurstrat.eu/chinas-peaceful-rise-and-the-goodneighbor-policy/ adresinden erişilmiştir.

Chinese President Xi speaks at Mongolian parliament. (2014). CGTN America, 29.11.2018 tarihinde https://america.cgtn.com/2014/08/22/chinesepresident-xi-speaks-at-mongolian-parliament adresinden erişilmiştir.

Chaisse, J. (2018). China's belt and road initiative: Mapping the World's normative and strategic implictaions. Journal of World Trade, 52(1),163186.

Chao, C. ve Chih-Chia H. (2008). "The worldviews of Chinese Leadership and Sino-US Relations, (Ed. Suisheng Zhao.), China and the United States içinde (s.81-105).Palgrave Macmillan:New York.

China Council for International Cooperation on Environment and Development (2013), Important Speech of Xi Jinping at Peripheral Diplomacy Work Conference, 01.12.2018 tarihinde http://www.cciced.net/cciceden/NEWSCENTER/LatestEnvironmentalandDevelopmentNews/201310/t20131030_82626.html adresinden erişilmiştir.

China Daily. (2017). Keywords from China's major-country diplomacy: China's neighboring \& African policy, 29.11.2018 tarihinde http://www.chinadaily.com.cn/china/2017-09/15/content_32039501 .htm adresinden erişilmiştir.

Dunne, T., Milja, K. ve Steve, S. (2016). Uluslararası ilişkiler teorileri: Disiplin ve çeşitlilik, (Çev. Ö. Keleçi), Sakarya Üniversitesi Kültür Yayınları.

Durdular, A. (2016). Çin'in kuşak-yol projesi ve Türkiye-Çin ilişkilerine etkisi. Avrasya Etüdleri, 49(1), 77-97.

Embassy of the People's Republic of China in the Commonwealth of Australia (2017), Xi Jinping Delivers Report to CPC Congress, 29.11.2018 tarihinde http://au.china embassy.org/eng/gdtp_ 16/t1502670.htm adresinden erişilmiştir.

Embassy of the People's Republic of China in the Republic of Indonesia (2015). Joint Statement on strengthening comprehensive strategic partnership between the people's Republic of China and The Republic of Indonesia, 12.12.2018 tarihinde http://id.china-embassy.org/eng/ zgyyn/zywx/t1249223.htm adresinden erişilmiştir.

Geis, J. P. ve Blaine, H. (2009). Harmonious society: Rise of the New China." Strategic Studies Quarterly, 3(4), 75-94. 
Goldstein, Joshua S.; Jon C. P. (2015). Uluslararası İlişkiler, (Çev. Haluk Özdemir), Ankara: BB101 Yayınları.

Greer, T. (2018). "One Belt, One Road, One Big Mistake”, Foreign Policy, https://foreignpolicy.com/2018/12/06/bri-china-belt-road-initiativeblunder/ (Erişim: 19.08.2019).

Guoli, L. (2008). Domestic sources of China's emerging grand strategy. Journal of Asian and African Studies, 43(5), 543-561.

Guoli, L. (2003). Leadership transition and Chinese foreign policy. Journal of Chinese Political Science, 8(1\&2), 101-117.

Hasenclever, A.; Peter, M. ve Volker, R. (2000). Integrating Theories of International Regimes. Review of International Studies, 26(1),3-33.

Jiangtao, S.; Churchill, O. (2018). US competes with China's 'Belt and Road Initiative' with US\$113 million Asian investment programme", South China Morning Post, 31.10.2018 tarihinde https://www.scmp.com/news/china/economy/article/2157381/us-competes-chinas-belt-androad-initiative-new-asian-investment adresinden erişilmiştir.

Keohane, R. O. (1984). After hegemony: Cooperation and discord in the World Political Economy, Princeton University Press: Princeton, New Jersey.

Keohane, R. O.; Joseph S. N. (1977). Power and Interdependence, Boston: Little Brown.

Krasner, S. D. (1983). International regimes. Cornell University Press: USA.

Lanteigne, M. (2009). Chinese Foreign Policy: An Introduction, Routledge.

Liang, X. (2018). The Six-Party Talks at a Glance, Arms Control Association, 05.11.2018 tarihinde https://www.armscontrol.org/factsheets/6partytalks adresinden erişilmiştir.

Liping, S. (2017). China'a approach to its neighbors in Xi's New Era, 02.12.2018 tarihinde https://moderndiplomacy.eu/2017/11/23/china-s-approachto-its-neighbors-in-xi-s-new-era/ adresinden erişilmiştir.

Mearsheimer, J. J. (2001). The tragedy of great power politics. New York: Norton. NDTV (2017). Pakistan will be our 'priority' in neighbourhood diplomacy: China, 12.12.2018 tarihinde https://www.ndtv.com/world-news/pakistan-will-be-our-priority-in-neighbourhood-diplomacy-china1778202 adresinden erişilmiştir.

Nien-chung, C. L. (2016). China's new foreign policy under Xi Jinping, Asian Security, 12(2), 82-91. 
Olsen, K. (2019). “China's defense spending is growing more slowly. But that doesn't mean military tensions are easing", CNBC, https://www.cnbc.com/2019/03/05/china-defense-budget-slowinggrowth-in-2019-military-spending-.html (Erişim: 19.08.2019).

Organski, A.F.K. (1958). World politics. New York Knopf.

Qi, H. (2015). China debates the new type of great power relations. The Chinese Journal of International Politics, 8(4), 349-370.

Pekcan, C. (2017). "Konfüçyüs Felsefesinin Dış Politikaya Etkisi Bağlamında 2003-2013 Yılları Arasında Çin-ABD İlişkileri”, Ankara Üniversitesi SBF Dergisi, 72(4), 1127-1155.

Rühlig, T. (2018). A 'New' Chinese foreign policy under Xi Jinping', Institute for SecurityEDevelopment Policy, 18.08.2019 tarihinde http://isdp.eu/publication /new-chinese-foreign-policy-xi-jinping-implications-european-policy-making/ adresinden erişilmiştir.

Stein, A. A. (2008). Neoliberal Institutionalism. Eds. Christian Reus-Smit and Duncan Snidal) The Oxford Handbook on international relations içinde (s. 201-221.), New York: Oxford University Press.

$\mathrm{Su}, \mathrm{H}$. (2009). Harmonious world: The conceived international order in framework of China's foreign affairs. (Ed. Masafumi Iida), China's Shift: Global Strategy of the Rising Power, içinde (s. 29-55.), NIDS Joint Research Series, No.3.

Suisheng, Z. (2012). Hu Jintao's foreign policy legacy. E-International Relations, 14.11.2018 tarihinde https://www.e-ir.info/2012/12/08/hu-jintaos-foreign-policy-legacy/ adresinden erişilmiştir.

Swaine, M. D. (2014). Chinese Views and Commentary on Periphery Diplomacy. China Leadershp Monitor, No.44.

Szczudlik-Tatar, J. (2015). Dual-track neighbourhood policy: Solidifying China's leadership in Asia, The Polish Institute of International Affairs, 758(26).

What is China's Belt and Road Initiative (2018). The Guardian. 29.11.2018 tarihinde https://www.theguardian.com/cities/ng-interactive/2018/jul/30/what-china-belt-road-initiative-silk-road-explainer adresinden erişilmiştir.

Putin and $\mathrm{Hu}$ Resolve Border Disputes. (2004). The New York Times. 14.11.2018 tarihinde https://www.nytimes.com/2004/10/15/world/asia/putinand-hu-resolve-border-disputes.html adresinden erişilmiştir. 
The World Bank. (2019). The World Bank in China, 18.09.2019 tarihinde https://www.worldbank.org/en/country/china/overview adresinden erişilmiştir.

Tonesson, S. (2012). China's boomerang Diplomacy, 10.12.2018 tarihinde https://yaleglobal.yale.edu/content/chinas-boomerang-diplomacy adresinden erişilmiştir.

United Nations Summit. (2005). Statement by H.E. Hu Jintao President of the People's Republic of China At the United Nations summit New York, 07.11.2018 tarihinde http://www.un.org/webcast/summit2005/statements15/china050915eng.pdf adresinden erişilmiştir.

Wiltse, E. Ç. (2014). Liberalizm, İşbirliği, kolektif güvenlik ve neoliberal kurumsalcllık. (Ed. Evren Balta), Küresel Siyasete Giriş: Uluslararası İlişkilerde Kavramlar, Teoriler, Süreçler içinde (s. 137-141.) İstanbul: İletişim Yayınları.

Xiaobo, H. (2018). China's relations with its neighbours, Encylopedia Britannica, 14.11.2018 tarihinde https://www.britannica.com/topic/ChinasRelations-with-Its-Neighbors-1106231 adresinden erişilmiştir.

Xue, L. ve Zheng, Y. (2016). A blueprint for China's neighbourhood diplomacy. The Diplomat, 12.12.2018 tarihinde https://thediplomat.com/2016/03/a-blueprint-for-chinas-neighborhood-diplomacy/ adresinden erişilmiştir.

Xulong, C. (2013). Xi Jinping opens a new era of China's periphery diplomacy. US-China Focus, 10.12.2018 tarihinde http://www.chinausfocus.com/foreign-policy/xin-jinping-opens-a-new-era-of-chinas-periphery-diplomacy/ adresinden erişilmiştir.

Young, O. R. (1989). International cooperation: Building regimes for natural resources and the environment. Cornell University Press: New York.

Zhang, C. (2013). Historical changes in relations between China and its neigboring countries (1949-2012), Asia Paper, Institute for Security and Development Policy.

Zhang, J. (2015). China's new foreign policy under Xi Jinping: Towards peaceful Rise 2.0'?, Global Change, Peace \& Security, 27(1), 5-19. 


\section{Kaynakça Bilgisi / Citation Information}

Pekcan, C (2019). Yeni-liberal kurumsalcılık çerçevesinde Çin'in komşuluk diplomasisi: Hu Jintao ve $\mathrm{Xi}$ Jinping dönemlerine karşılaştırmalı bir bakış. OPUS-Uluslararası Toplum Araştırmaları Dergisi, 13(19), 2867-2892. DOI:10.26466/opus.594562 